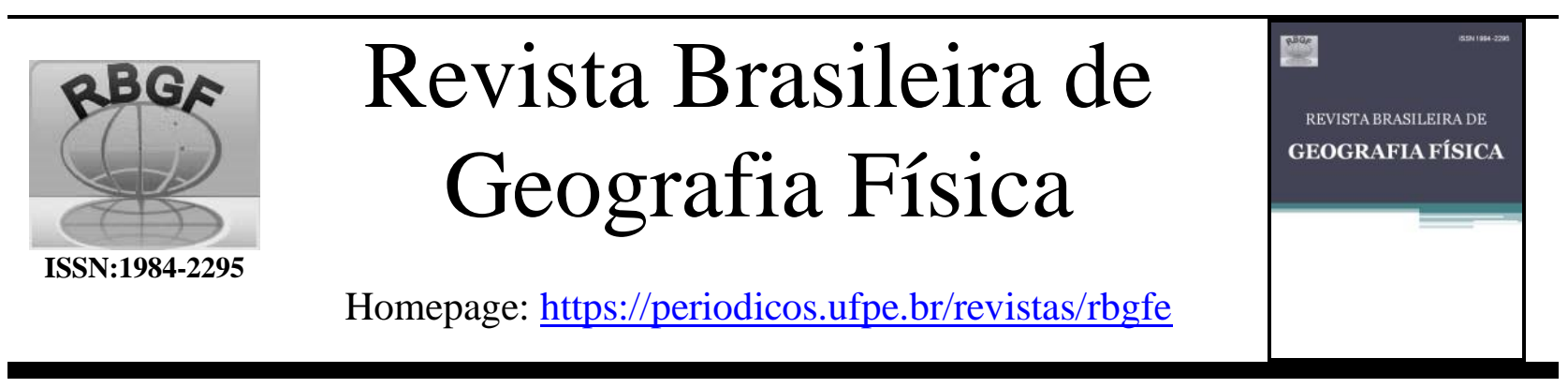

\title{
Análise da susceptibilidade a alagamento em Juazeiro do Norte, Ceará
}

\author{
Orjana Dias Palácio ${ }^{1}$, Carlos Wagner Oliveira ${ }^{2}$, Ana Célia Maia Meireles ${ }^{3}$, Teobaldo Gabriel de Souza Júnior ${ }^{4}$
}

\begin{abstract}
${ }^{1}$ Ma. em Desenvolvimento Regional Sustentável, Bacharel em Engenharia Ambiental pelo Instituto Federal de Educação, Ciência e Tecnologia do Ceará, Juazeiro do Norte. (88) 99755-8114. orjana.palacio@ aluno.ufca.edu.br (autor correspondente). ${ }^{2}$ PhD. em Biosystems Engineering, Professor da Universidade Federal do Cariri, Campus Crato, R. Ícaro de Sousa Moreira, 126, Muriti, CEP 63130-025, Crato, Ceará. (88) 99802-3222. carlos.oliveira@ufca.edu.br. ${ }^{3}$ Dra. em Engenharia Civil, Professora da Universidade Federal do Cariri, Campus Crato, R. Ícaro de Sousa Moreira, 126, Muriti, CEP 63130-025, Crato, Ceará. (85) 99969-7818. ana.meireles@ufca.edu.br. ${ }^{4}$ Me. em Desenvolvimento Regional Sustentável, Professor do Instituto Federal de Educação, Ciência e Tecnologia da Paraíba, R. José Antônio Pessoa, 300, Lot. dos Médicos, CEP 58900-000, Cajazeiras, Paraíba. (88)99925-0033. teobaldo.ebm@ hotmail.com.
\end{abstract}

Artigo recebido em 19/05/2021 e aceito em 27/07/2021.

\section{R E S U M O}

Este estudo aborda a relação de casualidade dos padrões de crescimento urbano com fenômenos ambientais, os quais tem nos Sistemas de Informações Geográficas (SIG) uma poderosa ferramenta de suporte ao planejamento urbano e à tomada de decisão. Neste sentido, a análise de susceptibilidade a alagamentos de regiões por meio de SIG representa uma informação importante para o poder público, como suporte ao processo de zoneamento urbano, de delimitação de áreas de risco e para a alocação de recursos públicos, com finalidade corretiva e preventiva. Desta forma, este estudo teve como objetivo determinar as áreas susceptíveis a alagamentos no município de Juazeiro do Norte, Ceará, através de técnicas de geoprocessamento. Para tanto foram utilizados dados de declividade, elevação, fluxo de água acumulada, curva número, tipo de solo e uso e ocupação do solo. Os resultados indicaram que Juazeiro do Norte é uma cidade de média susceptibilidade a alagamento, correspondendo a $69 \%$ do município, além de comprometer de forma elevada $17 \%$. Da área urbana, o bairro Tiradentes merece alerta pelo maior potencial a alagamento, onde 79, $5 \%$ de sua área está totalmente vulnerável. O mapa gerado serve como um instrumento de gestão e monitoramento de eventos hídricos extremos que acontecem rotineiramente na cidade. Ele também sinaliza a comunidade e gestores a tomarem medidas de prevenção e minimização do alagamento.

Palavras-chaves: Fenômeno Hidrológico, Vulnerabilidade, SIG

\section{Analysis of susceptibility to flooding in Juazeiro do Norte, Ceará}

\begin{abstract}
A B S T R A C T
This study addresses the casual relationship between urban growth patterns and environmental phenomena, which we have in Geographic Information Systems (GIS) as a powerful tool to support urban planning and decision-making. In this sense, an analysis of susceptibility to flooding of regions through GIS represents important information for the public sector, as support to the urban zoning process, delimitation of risk areas and for the allocation of public resources, with corrective and preventive purposes. Thus, this study aimed to determine areas susceptible to flooding in in the municipality of Juazeiro do Norte, Ceará, through geoprocessing techniques. For that purpose, data on slope, elevation, accumulated water flow, curve number, soil type and land use and occupation were used. The results indicated that Juazeiro do Norte is a city of medium susceptibility to flooding, corresponding to $69 \%$ of the municipality and compromising $17 \%$ in a high susceptibility. The urban area of the Tiradentes neighborhood deserves alert due to its greater potential for flooding, where $79.5 \%$ of its area is very vulnerable. The generated map serves as an instrument for managing and monitoring extreme water events that happen routinely in the city. It also signals the community and managers to take measures to prevent and minimize flooding.
\end{abstract}

Keywords: hydrological phenomenon, vulnerability, GIS

\section{Introdução}

As pressões da pobreza, o crescimento populacional nas grandes metrópoles, e o direito desigual da terra forçam as pessoas a ocuparem áreas de risco, como encostas íngremes ou margens de rios. $\mathrm{Na}$ ocorrência de um desastre, as consequências se acentuam, tomando grandes 
proporções sobre aqueles que menos têm acesso aos bens materiais básicos e principalmente autonomia emancipatória (Londe et al., 2018; Silva et al., 2019). Entre os desastres naturais que mais acontecem nas cidades urbanas, o alagamento é o segundo desastre em destaque, chegando a atingir $31 \%$ dos municípios brasileiros (IBGE, 2018). Através de pesquisas em escala global foi relatado cerca de 200 milhões de pessoas são afetadas anualmente pelo alagamento (Bui et al., 2019)

Dentre os efeitos adversos, o alagamento pode causar danos socioeconômicos, ambientais e até mesmo perda de assentamentos humanos (Dano et al., 2019; Costache et al., 2020; Domakinis et al., 2020; Tien Bui et al., 2020). Na ocorrência dos impactos ambientais, como a poluição hídrica, o alagamento impulsiona a expansão de zonas de proliferação de vetores de doenças, que afetam diretamente a saúde pública (Sweya e Wilkinson, 2020). Os sistemas agrícolas, de produtividade, renda e segurança alimentar também podem ser afetados, causando problemas de baixa renda e segurança alimentar (Wu et al., 2019).

$\mathrm{O}$ agravamento dos cenários de inundação e a motivação no surgimento de novos pontos de alagamento podem ser associados a vários fatores dinâmicos, como volume pluvial escoamento, capacidade de infiltração do solo, declividade, evapotranspiração, mudanças no clima e mudanças nos padrões de uso da terra (Costache, 2019; Ali et al., 2020). A fim de avaliar o zoneamento do alagamento e análise da sensibilidade em cada região, são necessários diferentes critérios para observar a relação entre cada um desses fatores e a ocorrência de alagamento (Avand et al., 2021). No entanto, esses critérios ou fatores condicionamento para análise da susceptibilidade podem mudar de acordo com a localização geográfica específica (Wang et al., 2019).

Embora o alagamento seja um desastre que não pode ser absolutamente evitado, o grau de consequências, efeitos adversos e a quantidade de perdas podem ser reduzidas por meio de análise da susceptibilidade a alagamento, prevendo áreas potencialmente alagadas (Ali et al., 2019). Nesse sentido, dados de sensoriamento remoto e sistema de informações geográficas (SIG) fornecem ferramentas que contribuem significativamente para a avaliação da vulnerabilidade ou susceptibilidade a alagamento de diversas áreas, como pode-se ver nos trabalhos de Vojtek e Vojteková (2019); Ali et al. (2020); Domakinis et al. (2020); Islam et al. (2020); Al-Hinai e Abdalla (2020); Yariyan et al. (2020); Wicaksono et al. (2021); Hussain et al. (2021). Por meio desses métodos é possível desenvolver banco de dados com maior precisão, aplicar técnicas de sensoriamento remoto em grandes áreas de difícil acesso e processar vários tipos de dados (Diaconu et al., 2021).

Infelizmente, a América do Sul é um dos continentes que menos se dedicaram a trabalhos que detectem áreas susceptíveis de alagamento (Diaconu et al., 2021). Além dessa carência, o Brasil pouco foi alvo desse tipo de análise. Inclusive, o estado do Ceará, não apresenta nenhum trabalho na análise de áreas potencialmente alagadas, já que há pouco desastre hidrológico na região, dado a sua semiaridez hidroclimatológica.

No entanto, o Cariri cearense foge desse característico semiárido (Moura-Fé et al., 2020). Parte de sua área é envolvida pela Chapada do Araripe aonde estende a disponibilidade de água durante o ano. Concomitantemente, a Região Metropolitana do Cariri (RMC) encontra-se com um quadro vulnerável relacionado à gestão das águas pluviais, visto às intensas taxas de impermeabilização do solo e ocupação urbana ao redor de cursos d'água, trazendo variados níveis de degradação ambiental (Moura-Fé et al., 2019).

Dos três municípios que compõem a RMC, Juazeiro do Norte possui a maior área urbanizada da região (Teles, 2018) e a quinta maior do estado (Pereira, 2013), sendo um grande fator condicionante para o alagamento (Hussain et al., 2021), visto que qualquer tipo de mudança no uso do solo resultante da urbanização leva a eventos de alagamento dado o aumento do coeficiente de precipitação escoada (Dammalage e Jayasinghe 2019). Nesse sentido, cabe ao presente estudo avaliar a problemática do alagamento no município de Juazeiro do Norte. O município possui uma medida territorial de aproximadamente $248,55 \mathrm{~km}^{2}$ e população aproximada de 271.926 habitantes (IBGE, 2018). O comportamento demográfico da cidade possui regime sazonal, intensificado pelas tradicionais romarias aonde, em alguns períodos do ano, a população chega a dobrar.

Portanto, o estudo visa utilizar SIG para detectar o grau de susceptibilidade a alagamento no município de Juazeiro do Norte, através de multicritérios de solo, uso e ocupação, declividade, elevação, fluxo acumulado de água e curva número. Para tanto, procura-se observar os potenciais prejuízos sociais e econômicos que esse evento pode ocasionar.

A pesquisa objetiva gerar dados que complementem e colaborem no desenvolvimento de medidas preventivas contra o alagamento de áreas identificadas como susceptíveis. Medidas essas, que proporcionem à redução de riscos de natureza hidrológica, previsão de danos e prevenção de acidentes, visto a importância de se 
planejar medidas eficientes e viáveis localmente para a mitigação de impactos e manutenção do equilíbrio ecossistêmico do meio urbano.

Diante disso, uma ferramenta poderosa de geotecnologia que pode ser utilizada é o SIG, pois permite analisar as áreas susceptíveis a alagamentos no município, em que classifica e integra espacialmente as variáveis envolvidas no fenômeno, gerando o mapa de susceptibilidade a alagamentos.

\section{Material e métodos}

Localização e Caracterização da Área Experimental
A área experimental encontra-se no município de Juazeiro do Norte, onde está localizada na região do Cariri, porção sudoeste do estado do Ceará.

Juazeiro do Norte faz fronteira ao Norte com o município de Caririaçu; ao Sul com os municípios de Crato, Barbalha e Missão Velha; a Leste, Missão Velha e Caririaçu; e a Oeste, o Crato.

Essa área de $219 \mathrm{~km}^{2}$ está inserida na carta topográfica Crato (SB.24-Y-DI), onde a Figura 1 destaca bem a localização do município de Juazeiro do Norte.

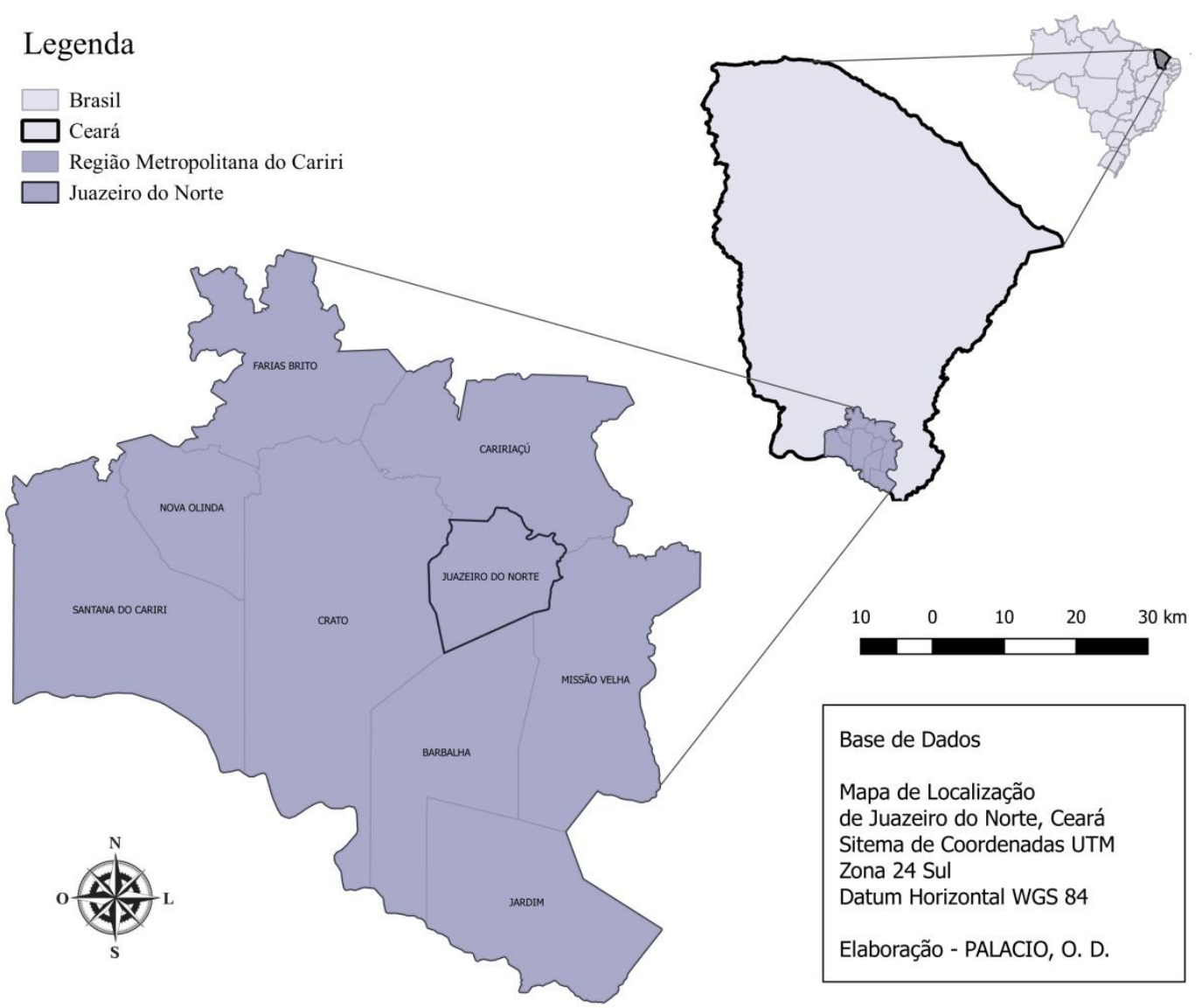

Figura 1. Localização geográfica do município de Juazeiro do Norte-CE, área experimental a ser avaliada.

O clima da região, segundo Köopen, é classificado como Aw', tropical seco, marcado pela distribuição irregular das chuvas durantes o ano. A estação chuvosa é compreendida entre os meses de janeiro e abril, precipitação média anual de $979 \mathrm{~mm}$ e temperaturas médias anuais, elevadas, da ordem de $26,7^{\circ} \mathrm{C}$ (INMET, 2020).

A área está sobre a bacia sedimentar do Araripe, de relevo de topo plano e completamente inserida na bacia hidrográfica do Sagado, com principais drenagens o rio Carás, riachos dos Macacos e Batateira e principal reservatório, açude Riacho dos Carneiros.
O rio Salgadinho e riacho das Timbaúbas são os afluentes da malha urbana, que por vezes, o rio Salgadinho encontra-se assoreado, com talvegue raso e fluxo efêmero. Os interflúvios são de baixa declividade, com a vertente ao sul crescente ocupação domiciliar, comercial e industrial.

O riacho das Timbaúbas atravessa um ambiente totalmente urbanizado, com vertentes ocupadas por oito bairros (Fátima, Pio XII, Franciscanos, Timbaúbas, Limoeiro, José Geraldo da Cruz, João Cabral e Lagoa Seca). O seu leito 
favorável a enchentes e solos úmidos garantem instabilidade às ocupações.

Etapas do Estudo

A metodologia utilizou-se da classificação espacial de variáveis pertinentes ao alagamento. Baseado no método AHP (Saaty, 1991) as variáveis foram selecionadas e aplicadas ao algoritmo de média ponderada, gerando pesos e hierarquizandoas.

O algoritmo classificador (média ponderada) foi aplicado a uma estrutura de matrizes, onde o somatório dos pesos dos planos de informações (variáveis) foi expresso no intervalo de 0 a 1 , significando a unidade.

Para que as variáveis sejam comparáveis, elas foram reclassificadas em cinco classes (5 muito alta, 4 - alta, 3 - moderada, 2 - baixa e 1 muito baixa) com base no potencial de contribuição da classe ao alagamento de áreas.

$\mathrm{O}$ potencial das classes foi avaliado e atribuído peso fundamentado nos trabalhos de Mahmoud e Gan (2018), Vojtek e Vojtekovád (2019), Dano et al. (2019), Ali et al. (2020), Wicaksono et al. (2021) e Hussain et al. (2021).

Foram selecionados 6 (seis) variáveis condicionantes para o alagamento, já que Mahmoud e Gan (2018) recomenda o uso de no mínimo 6 (seis) variáveis, para não produzir pesos não representativos por um único peso. Esse número de variáveis condicionantes também foram ajustados às condições físicas fidedignos a área de estudo, contemplando fatores pedológicos, morfológicos, hidrológicos e de impermeabilidade do município.

É importante salientar que os pesos das variáveis foram adaptados à realidade local, para avaliar o desempenho desse método, permitindo, de tal modo, a análise e discussão dos resultados obtidos.

Assim, foram elaborados mapas temáticos de cada variável condicionante ao alagamento e integrados por meio do algoritmo. Tanto o processamento das variáveis quanto a integração das imagens foram realizadas pelo pacote de ferramentas do QGIS 2.18 Las Palmas, usando o sistema de coordenadas UTM Zona 24 Sul e o sistema de referência WGS 84, além de extensões associadas.

A análise espacial dos dados foi trabalhada em raster com resolução $5 \times 5$ m.

Para atender um adequado desempenho no experimento foi estruturado um fluxograma de procedimentos (Figura 2).

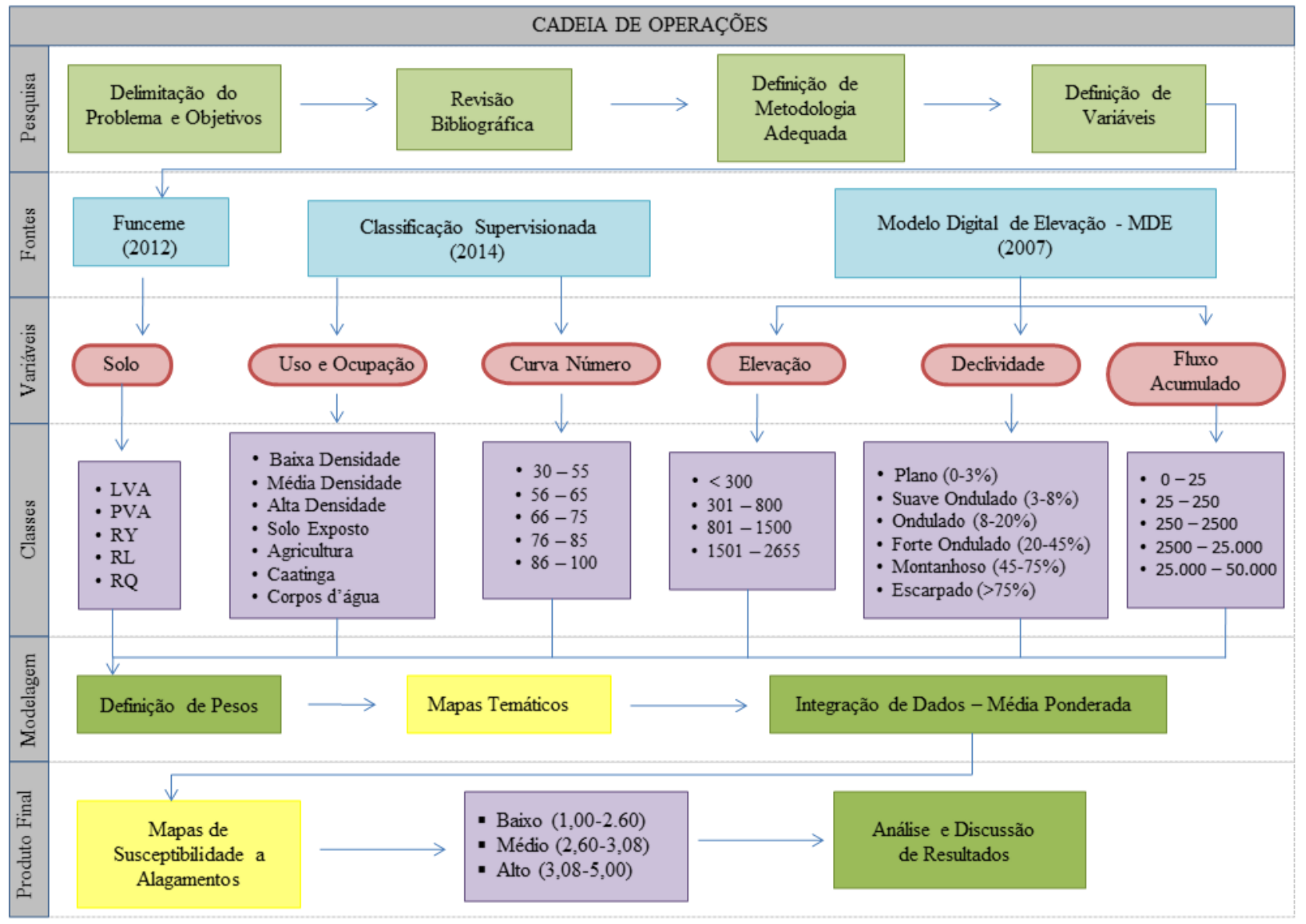

Figura 2. Fluxograma de procedimentos adotados no experimento. 
Classificação das Variáveis

Na seleção das variáveis condicionantes ao alagamento foram consideradas 4 (quatro) variáveis trabalhadas por Soares Neto et al. (2017) e mais 2 (duas) variáveis trabalhadas por Vojtek e Vojtekovád (2019), sendo elas: fluxo acumulado de água, elevação, declividade, solo, curva número e uso e ocupação.

Ambos destacaram a importância em adotar variáveis ligadas a hidrografia, hidrologia, morfometria e permeabilidade, já que constituem componentes ambientais intrínsecos aos processos de alagamento.

Nesse sentido, foi inferido valores de 0 a 1 às variáveis selecionadas, em função da importância adotada por Soares Neto et al. (2017) e Vojtek e Vojtekovád (2019) sobre os eventos de alagamento, mesclando a realidade de Juazeiro do Norte, Ceará

A Tabela 1 esmiúça as variáveis selecionadas, com seus devidos pesos (0 a 1$)$ e classes carregadas de peso também (1 a 5).

Tabela 1. Variáveis, Classes, Pesos das classes, Pesos das variáveis.

\begin{tabular}{|c|c|c|c|}
\hline Variáveis & Classes & Peso das Classes & Peso das Variáveis \\
\hline \multirow{5}{*}{ Solo } & Neossolo Quartizarenico & 1 & \multirow{5}{*}{0,05} \\
\hline & Latossolo Vermelho Amarelo & 2 & \\
\hline & Argissolo Vermelho Amarelo & 3 & \\
\hline & Neossolo Litólico & 4 & \\
\hline & Neossolo Flúvico & 5 & \\
\hline \multirow{7}{*}{ Uso e Ocupação } & Mata Ciliar & 1 & \multirow{7}{*}{0,2} \\
\hline & Caatinga Densa & 1 & \\
\hline & Caatinga Rala & 2 & \\
\hline & Solo Exposto & 3 & \\
\hline & Área Urbana & 4 & \\
\hline & Área Asfáltica & 5 & \\
\hline & Corpos d'água & 5 & \\
\hline \multirow{5}{*}{ Curva Número $(\mathrm{CN})$} & $30-55$ & 1 & \multirow{5}{*}{0,15} \\
\hline & $56-65$ & 2 & \\
\hline & $66-75$ & 3 & \\
\hline & $76-85$ & 4 & \\
\hline & $86-100$ & 5 & \\
\hline \multirow{4}{*}{ Elevação } & $<300$ & 5 & \multirow{4}{*}{0,1} \\
\hline & $301-800$ & 4 & \\
\hline & $801-1500$ & 3 & \\
\hline & $1501-2566$ & 2 & \\
\hline \multirow{5}{*}{ Declividade } & Plano $(0-3 \%)$ & 5 & \multirow{5}{*}{0,3} \\
\hline & Suave Ondulado $(3-8 \%)$ & 4 & \\
\hline & Ondulado $(8-20 \%)$ & 3 & \\
\hline & Forte Ondulado $(20-45 \%)$ & 2 & \\
\hline & Montanhoso (45-75\%) & 1 & \\
\hline \multirow{5}{*}{$\begin{array}{c}\text { Fluxo Acumulado de } \\
\text { Água }\end{array}$} & $0-25$ & 1 & \multirow{5}{*}{0,2} \\
\hline & $25-250$ & 2 & \\
\hline & $250-2500$ & 3 & \\
\hline & $2500-25.000$ & 4 & \\
\hline & $25.000-50.000$ & 5 & \\
\hline
\end{tabular}

Solo 
Considerando as características físicas genéricas de cada classe de solo, foram relevantes para o alagamento os fatores relacionados à velocidade de infiltração de águas.

Dependendo da combinação desses fatores, as águas pluviais apresentam maior tendência à infiltração ou ao escoamento quando entram em contato com determinada classe de solo (Soares Neto et al., 2017).

Sendo assim, foi extraída da FUNCEME (2012) a base de dados referente ao tema pedologia, para identificar os tipos de solos característicos de Juazeiro do Norte, gerando um mapa de solos do município.

Para essa variável foi adotado um grau de influência de $5 \%$.

\section{Uso e Ocupação}

De acordo com as mudanças exacerbadas nos padrões de uso da terra, as taxas de alagamento tendem a ser intensas até 2050, o que pode resultar numa perda de aproximadamente 1 trilhão de dólares na economia mundial (Jahandideh-Tehrani et al., 2019; Xu et al., 2019; Serraj et al., 2019). Essa previsão justifica-se pelos elevados níveis de cobertura e impermeabilização do solo, o que limitam as capacidades naturais de retenção das bacias e podem resultar em acelerados escoamentos superficiais ou processos de erosão (Sofia et al., 2017; Barros et al., 2021).

Seguindo esse parâmetro, dados de uso e ocupação foram gerados através do processo de Classificação Supervisionada, em prol de averiguar os tipos de cobertura e intervenção antrópica em Juazeiro do Norte. A imagem processada foi extraída em maio e junho de 2014 pelo satélite Rapideye, com resolução espacial de 5 metros, produto compatível com a escala de 1:25.000.

A classificação utilizou-se da ferramenta Semi-Atomatic Classification do software QGIS 2.18 Las Palmas, na qual a área de estudo foi dividida conforme as principais categorias de uso e ocupação que se encontram no município. $\mathrm{O}$ peso das classes foi designado de acordo com os níveis de impermeabilização e capacidade de infiltração.

Para essa variável foi adotado um grau de influência de $20 \%$.

\section{Curva Número}

O potencial de escoamento da bacia hidrográfica de Juazeiro do Norte foi mensurado pelo o Método Curva Número NRCS (1997). Esse método está diretamente relacionado a outras variáveis em análise nessa pesquisa, como, solo, condições de uso e ocupação, além da umidade antecedente e grupos hidrológicos de solo.
Para trabalhar com essa diversidade de dados, foi avaliada inicialmente a pedologia do município pelo mapa de solo já gerado. Perante as características locais encontradas foram determinados os grupos hidrológicos de solo de Juazeiro do Norte, seguindo as orientações de Sartori (2005). Em sequência foram fixados os valores de $\mathrm{CN}$ para bacias urbanas e suburbanas (Tucci et al, 1993), de acordo com o mapa de uso e ocupação do município já classificado.

Esses valores foram reclassificados em 5 (cinco) classes, categorizados com pesos correspondentes ao grau de escoamento de $\mathrm{CN}$.

$\mathrm{O}$ grau de influência adotado para essa variável foi de $15 \%$.

\section{Elevação}

A elevação é um dos fatores físicos ambientais mais importantes na previsão de alagamentos (Darabi et al., 2018; Costache, 2019; Yariyan et al., 2020).

Desse modo, os dados de elevação de Juazeiro do Norte foram extraídos a partir do MDE (Modelo de Elevação), na qual a imagem obtida pelo GLS Landsat-7 datada em 2007, foi interpolada pelas linhas de contorno e pontos de elevação. Os intervalos hipsométricos de 50 metros foram reclassificados em 4 (quatro) classes, de acordo com o trabalho de Vojtek e Vojtekovád (2019).

Para essa variável foi adotado um grau de influência de $10 \%$.

Declividade

Um dos componentes físicos de significativa influência para o alagamento é a declividade. E assim como a variável de elevação, a declividade foi derivada do MDE do terreno de Juazeiro do Norte, datado em 2007, com resolução espacial de 30 metros.

Após extração e tratamento da imagem foram definas 5 (cinco) classes de declividade e seguidas de pesos conforme o trabalho de Soares Neto et al. (2017), que considerou a variável de maior potencial para $\mathrm{o}$ alagamento.

De acordo com o trabalho de Diaconu et al. (2021) a declividade tem a maior influência sobre outros critérios (variáveis) para esse evento. Em vista disso, aplicou-se maior peso para essa variável no ato da integração de dados, adotando um grau de influência de $30 \%$.

\section{Fluxo Acumulado}

Assim também como a elevação e declividade, a variável de fluxo acumulado de água foi derivada do MDE de Juazeiro do Norte, datado 
em 2007, na qual passou por um processo de varredura para destacar a direção de fluxos.

$\mathrm{Na}$ varredura da imagem, cada unidade de pixel contém informações sobre o número de células que fluem para um determinado ponto em comum, o que significa, que cada célula é também um perfil de descarga. Nesse sentido, um aumento na acumulação de fluxo deve refletir um aumento na susceptibilidade a alagamento.

De acordo com o grau de fluxo acumulado foi definido classes de fluxos e seus correspondentes pesos. Esses pesos foram definidos conforme o trabalho de Soares Neto et al. (2017), variando as classes de fluxo do mínimo a muito alto.

Para essa variável foi adotada um grau de influência de $20 \%$.

Integração de Dados

A integração dos dados se deu através da aplicação do algoritmo de média ponderada e a sobreposição (combinação) das variáveis citadas, com vistas à identificação das áreas passíveis ao alagamento.

Para a agregação de variáveis foi inicialmente identificado a significância de cada variável com seus devidos pesos. A importância relativa às variáveis selecionadas foi atribuída com base em estudos bibliográficos já mencionados.

Em seguida atribui-se também peso às classes de cada variável, em que apresentaram graus distintos de contribuição para o fenômeno estudado.

Com o auxílio do QGis 2.18, a média ponderada foi aplicada para os pesos das classes e aos pesos de suas variáveis correspondentes, efetivando a sobreposição das imagens de solo, uso e ocupação, curva número, elevação, declividade e fluxo acumulado.

A unificação dos pixels agregados e sobrepostos gerou um mapa de susceptibilidade a alagamento para Juazeiro do Norte, com classes variando de baixa a alta susceptibilidade.

Foram testadas diferentes combinações de pesos de classes e de variáveis, afim de encontrar um melhor resultado semelhante as áreas afetadas por alagamento no município.

\section{Resultados e discussão}

Análise das Variáveis Condicionantes ao Alagamento

De acordo com os objetivos deste trabalho foi possível através de geotecnologias obter mapas temáticos e integrá-los em prol de identificar e analisar a susceptibilidade a alagamento em Juazeiro do Norte.
São descritos, a seguir, os mapas temáticos das variáveis condicionantes, como proposto na metodologia apresentada.

\section{Mapa de Solos}

É sabido que, dependendo das classes de solo de um local, as águas pluviais podem apresentar uma maior tendência à infiltração ou ao escoamento. Ou seja, o perfil de drenagem característico de um solo aumenta ou diminui sua capacidade de infiltração de água quando entra em contato com um substrato de solo específico.

Acompanhando esses critérios, com a metodologia proposta, foi identificado 4 (quatro) classes de solos em Juazeiro do Norte de acordo com a Figura 3.

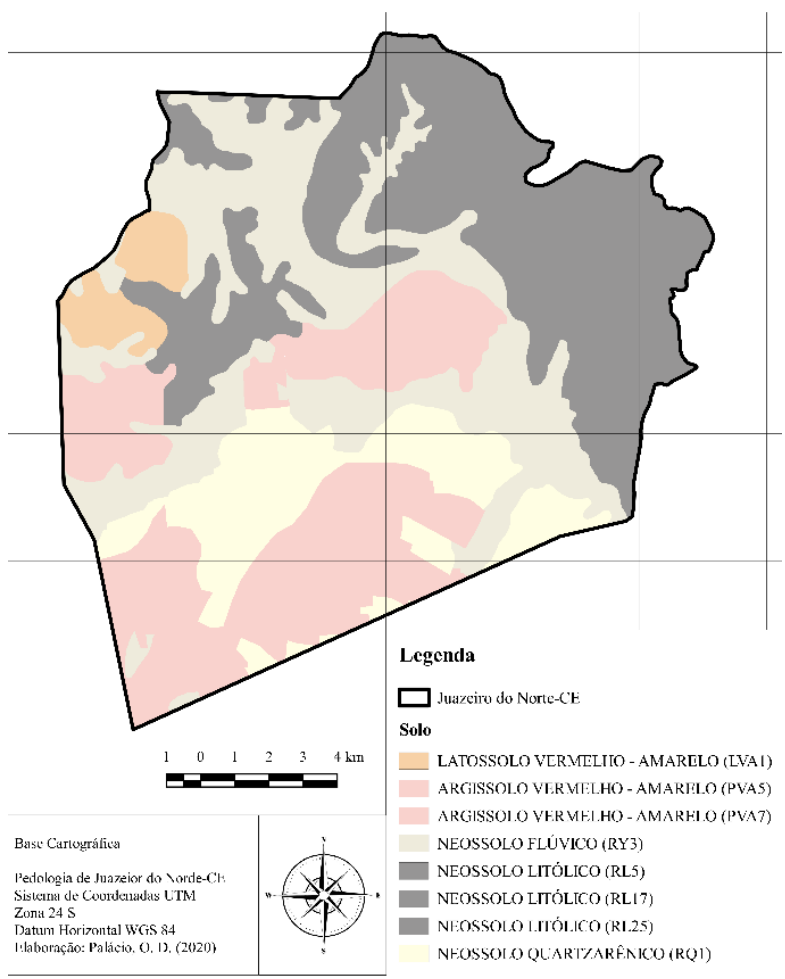

Figura 3. Classes de Solos de Juazeiro do Norte.

A distribuição das classes pedológicas no município procede-se da seguinte forma; a área urbana ao norte envolvida por Neossolos Quartizarênicos (peso 1), e ao sul por Argissolos Vermelho Amarelos (peso 3).

Os Neossolos Quartizarênicos apresentem alta permeabilidade e bastantes tendenciosos a infiltração, na contra mão, há os Argissolos, que são tendenciosos ao escoamento superficial, que, somada a cobertura com pavimentação asfáltica são mais decisivos a eventos de alagamento em períodos chuvosos ao sul da cidade. A área rural é tomada ao leste por Neossolos Litólicos (peso 4), a oeste por Neossolos Flúvicos (peso 5) e Latossolos 
Vermelho Amarelos (peso 2); e centro-oeste por Argissolos Vermelho Amarelos (peso 3).

A área onde se concentra os Neossolos Litólicos e Neossolos Flúvicos há várias acumulações de corpos hídricos, como o açude Riacho dos Carneiros, na qual justifica sua elevada capacidade de escoamento e risco de inundações em períodos chuvosos. Já nas áreas que se concentram os Latossolos Vermelho Amarelos são solos excessivamente drenados, com alta permeabilidade. Os Argissolos Vermelho Amarelos, na área mais central, são caracterizados por solos de baixa a média permeabilidade, em que explica seu peso mediano adotado no trabalho.

\section{Mapa de Uso e Ocupação \\ Pelo método de Classificação} Supervisionada foi possível dividir o município de Juazeiro do Norte em sete classes principais de uso e ocupação seguindo a representação do mapa da Figura 4. É válido ressaltar novamente que, o peso dado a cada classe foi baseado no nível de impermeabilização e na aptidão de escoamento das águas pluviais.

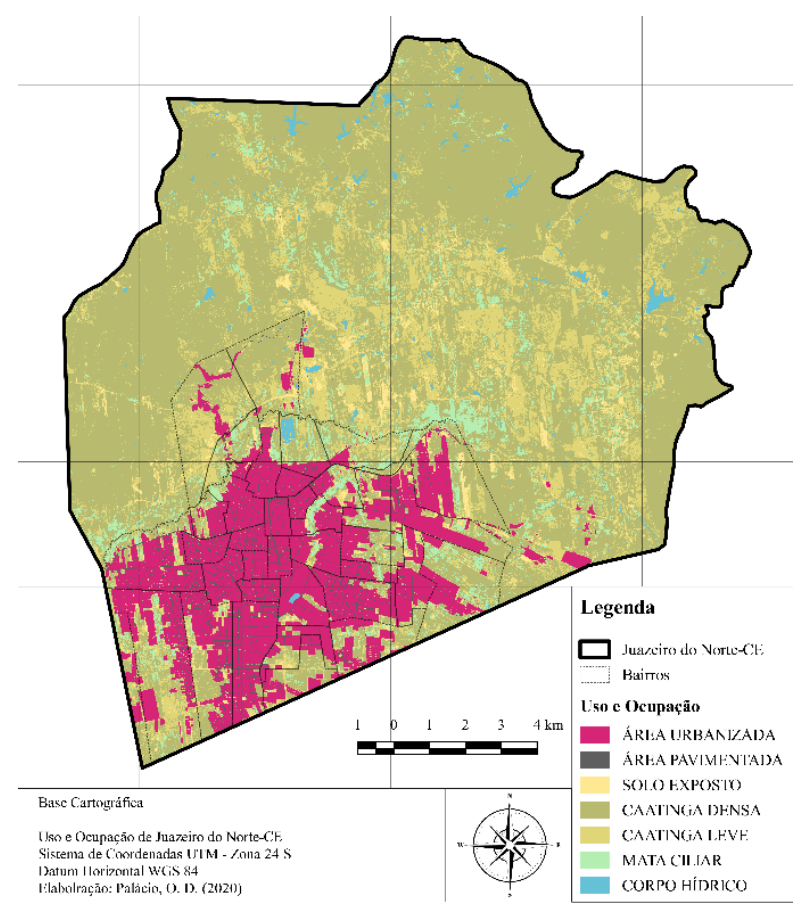

Figura 4. Classes do Uso e Ocupação de Juazeiro do Norte.

Dos resultados, temos a área urbana (peso 4) e pavimentada (peso 5) concentradas ao sudoeste do mapa, cobrindo aproximadamente $18,4 \%$ da área total do município. Seus pesos se justificam pela elevada cobertura impermeável, sendo que, a área urbana está com 1 (um) peso a menos por apresentar algumas áreas de amortecimento, seja nas edificações ou em terrenos baldios.

Nota-se pela imagem que a classe de solo exposto (peso 3) é mais frequente na região central do município, cobrindo aproximadamente $1 \%$ da área total. Seu peso médio justifica-se pela falta de cobertura que potencializa o escoamento superficial e consequentemente eleva a suscetibilidade do alagamento. Verifica-se também que a caatinga rala (peso 2) está distribuída na região central do mapa, com maior abrangência que o solo exposto, cobrindo $14,3 \%$ da área total, o que favorece a infiltração pluvial nas zonas rurais.

A caatinga densa (peso 1) é a classe que tem maior abrangência no município, cobrindo $62 \%$ da área total, porém é praticamente inexistente a presença dessa classe na zona urbana, diferente das duas cidades vizinhas (Crato e Barbalha), que são bem mais próximas a Chapada do Araripe e consequentemente, recebem maiores influências dessa importante cobertura vegetal.

Outra classe de grande relevância para qualquer ambiente natural ou urbano é a mata ciliar (peso 1). Essa classe cobre 3,3\% do município, acompanhando o trajeto dos cursos d'água que cortam parte da área urbana, favorecendo o amortecimento das águas pluviais nesta porção.

A última cobertura classificada, corpo hídrico (peso 5), está localizada e mais presente na zona rural do município. A zona urbana conta com a presença de dois corpos hídricos, o rio Salgadinho e riacho das Timbaúbas.

Os corpos hídricos possuem maior peso por já se configurarem como espaços alagados, aonde há níveis de impermeabilização que inviabiliza a infiltração de água durante o ano.

\section{Mapa de Curva Número}

Tendo já conhecimento dos solos característicos do município, os grupos hidrológicos que se enquadraram a essa realidade foram: Grupo A (LATOSSOLO VERMELHO AMARELO), Grupo B (NEOSSOLO QUARTZARÊNICO), Grupo C (ARGISSOLO VERMELHO AMARELO e NEOSSOLO FLÚVICO) e Grupo D (NEOSSOLO LITÓLICO).

Com base nesses grupos hidrológicos, o conjunto de valores de $\mathrm{CN}$ foi fixado e reclassificado em 5 cinco classes de acordo com o potencial de escoamento. Os intervalos de $\mathrm{CN}$ estão distribuídas espacialmente conforme o mapa da Figura 5. 


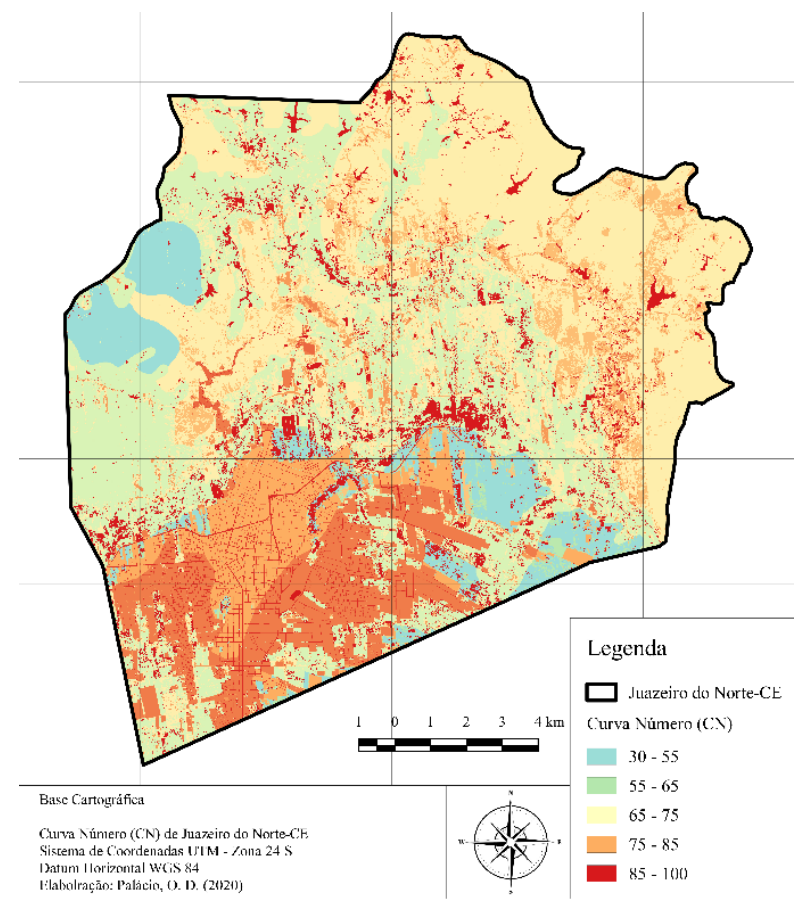

Figura 5. Classes de Curva Número presentes em Juazeiro do Norte.

Dos resultados obtidos, tem-se a área urbana dividida em 2 (dois) tipos de zonas de escoamento. A maior zona de escoamento envolve os bairros: São José, Tiradentes, Betolândia, Cidade Universitária e Novo Juazeiro. Seus valores de $\mathrm{CN}$ variam de 86 a 100 , indicando elevados índices de escoamento pluvial e consequentemente, elevada susceptibilidade a alagamento. Outra zona com escoamento elevado, tem seus valores de $\mathrm{CN}$ variando entre 76 a 85 . Essa zona envolve parte do bairro Aeroporto e grande porção da área urbana central, acoplando os bairros: Triângulo, Centro, Pirajá, Limoeiro. Esses dois intervalos estão similares aos valores de CN indicados no trabalho de Fernandes et al. (2017), em que variam de 70 a 95, para vazões máximas de escoamento em Juazeiro do Norte.

Os valores intermediários de $\mathrm{CN}$ vão de 66 a 75 , onde são mais direcionados ao leste do município. Em contra partida tem os valores mais baixos de $\mathrm{CN}$ que estão entre 30 a 65 , atingindo o norte e oeste do município e nos contornos da área urbana, o que significa menor possibilidade de haver escoamento pluvial.

\section{Mapa de Elevação}

A reclassificação do MDE de Juazeiro do Norte identificou 4 (quatro) classes de elevação, com valores variando de 344 a 506 metros (Figura 6). Resultados semelhantes aos de Evangelista et al. (2019), variando de 401 a 550 metros, em que se justificam pelas áreas de depressão circundadas à Chapada do Araripe.

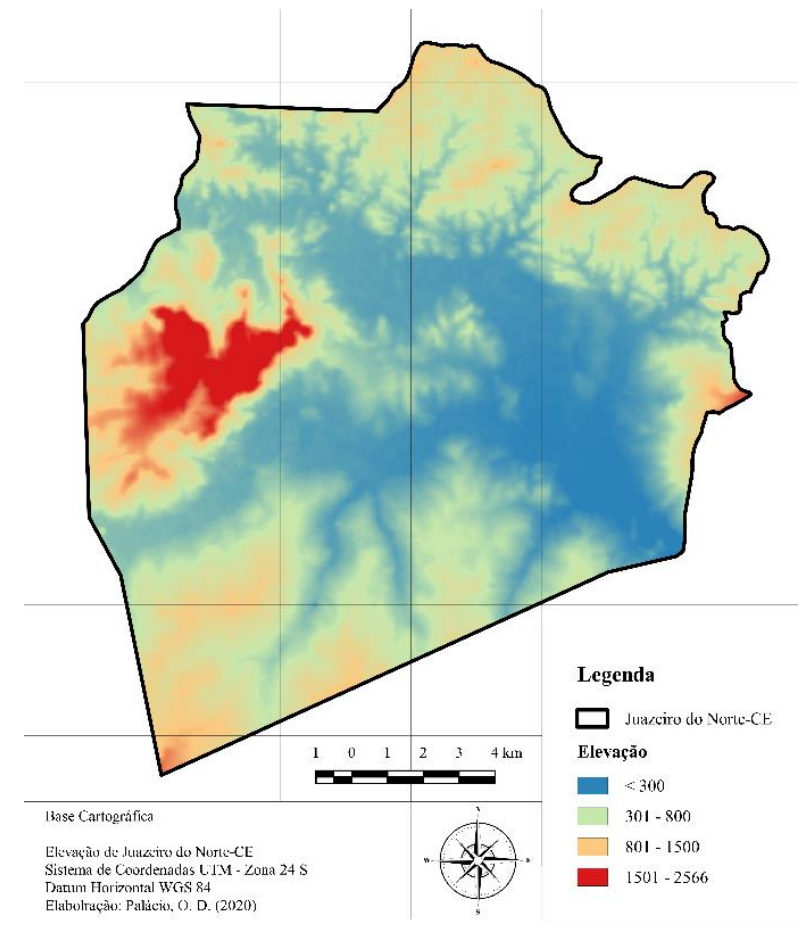

Figura 6. Classes de Elevação em Juazeiro do Norte.

Dos valores obtidos, o de maior peso (influência) se refere à classe de menor valor numérico de elevação, já que essa variável é inversamente proporcional à suscetibilidade ao alagamento.

Dessa maneira, de acordo com os resultados, a classe de menor valor é localizada na zona rural do município, cortando a porção leste da cidade, com maior potencialidade a evento hidrológicos nessas áreas. As maiores elevações estão localizadas em áreas próximas ao horto, com menor peso de influência para o alagamento.

\section{Mapa de Declividade}

Assim como a variável elevação, o mapa de declividade foi gerado através do modelo de elevação de Juazeiro do Norte, acompanhando seis classes com influência inversa sobre o alagamento. A Figura 7 ilustra a distribuição espacial dessas classes. 


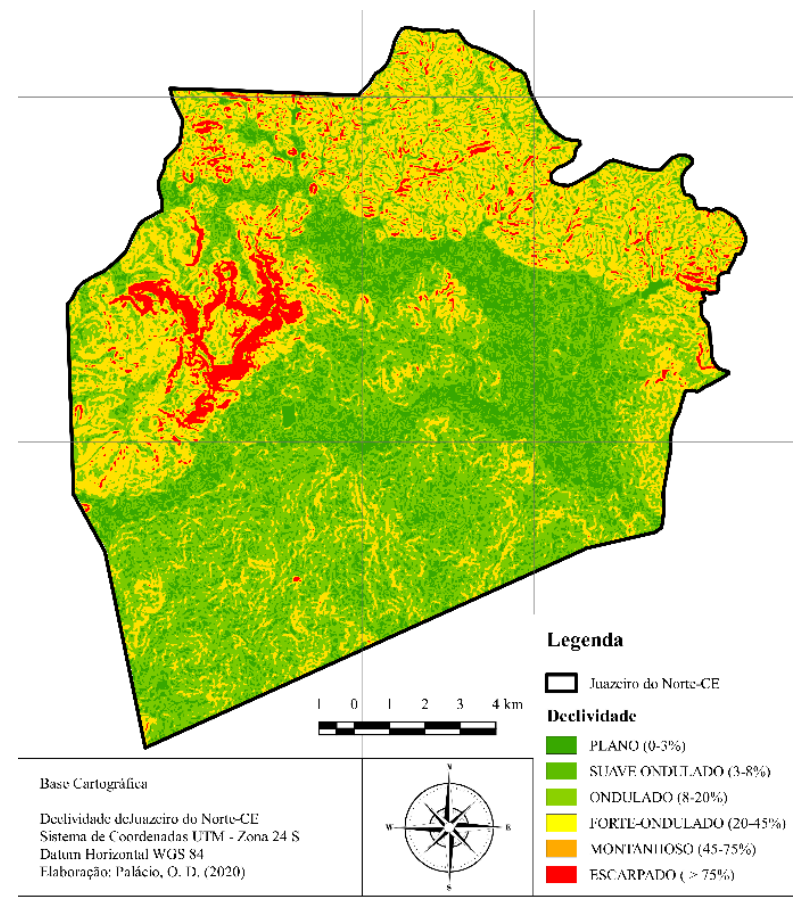

Figura 7. Classes da Declividade de Juazeiro do Norte.

Em grande parte da extensão, o município é composto por áreas planas (0-3\% de declividade), sendo bastante tendencioso ao evento em questão. Fora isso, as áreas de declividade fortemente onduladas $(20-45 \%)$ e pequenas porções de escarpado ( $>75 \%$ de declividade) se concentram ao norte do município, com menor tendência ao alagamento.

Esses valores estão similares aos de Evangelista et al. (2019), que propôs o mapeamento geomorfológico do Cariri derivado do MDE da região, incluído Juazeiro do Norte.

É importante relembrar que essa variável em especial, apresenta maior peso para a combinação de variáveis (integração) e consequentemente, maior influência sobre a suscetibilidade a alagamento. Nesse sentido, como a área urbana de Juazeiro apresenta menores elevações do CRAJUBAR (Juazeiro do Norte, Crato e Barbalha), consequente, menores também as declividades, formando um aporte de grande peso para este evento hidrológico.

Mapa de Fluxo Acumulado

A segunda variável de maior relevância ao evento estudado foi também derivada do MDE de Juazeiro do Norte e da varredura das direções dos fluxos.

Conforme os resultados, o grau de acúmulo de fluxo foi dividido em 5 classes (Figura 8), variando o fluxo de mínimo a muito alto.

Esta variável é bem simples de compreender, já que quanto maior a acumulação de fluxo d'água, maior será a susceptibilidade ao alagamento.

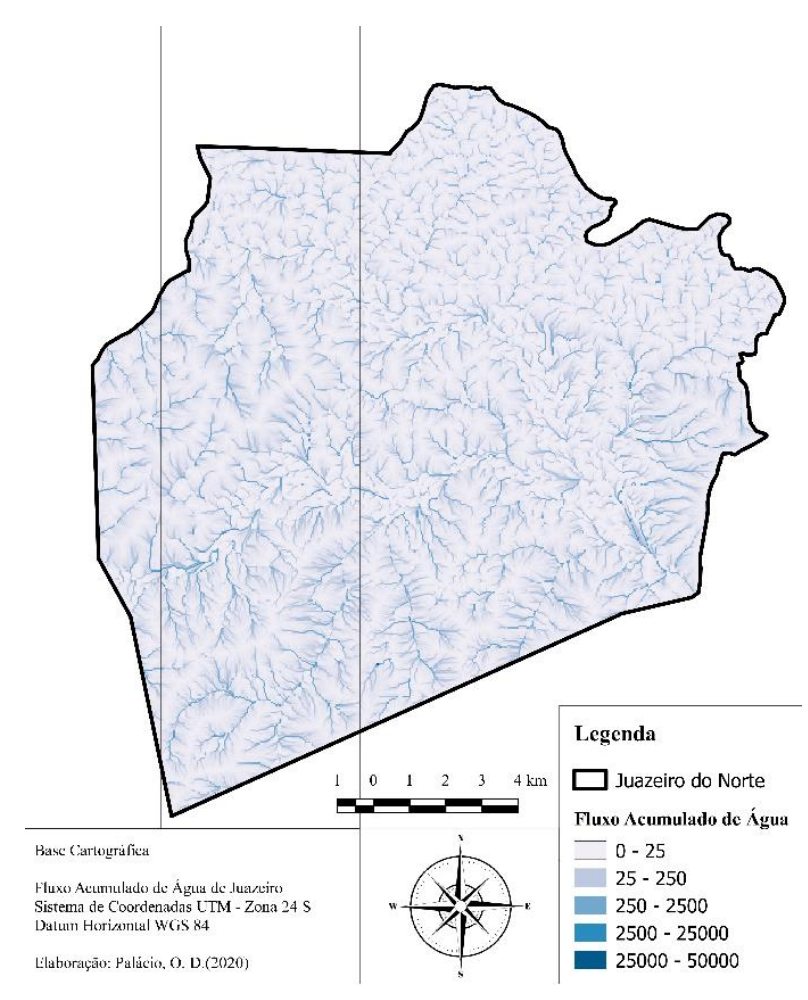

Figura 8. Classes do Fluxo Acumulado de Juazeiro do Norte.

Ao longo de toda a extensão do mapa abaixo, há diversas ramificações e alcance de fluxos acumulados. No entanto, a maior concentração de fluxos está direcionada ao sul do município, com longos cursos d'água que atingem a área urbana.

Como Juazeiro do Norte possui as menores elevações entre as cidades do CRAJUBAR, grande parte das águas que nascem da Chapada do Araripe e cortam a RMC, são direcionadas para Juazeiro do Norte, gerando um grande acúmulo de água escoada.

Integração de Variáveis

Com a sobreposição de todas as variáveis descritas, sempre seguindo bases de modelos recomendados na literatura, foram identificadas três principais classes susceptíveis ao processo de alagamento em Juazeiro do Norte. As classes percorreram os níveis de susceptibilidade entre: baixa, média e alta, conforme aptidão da área em acumular água. $\mathrm{O}$ resultado está representado na Figura 9. 


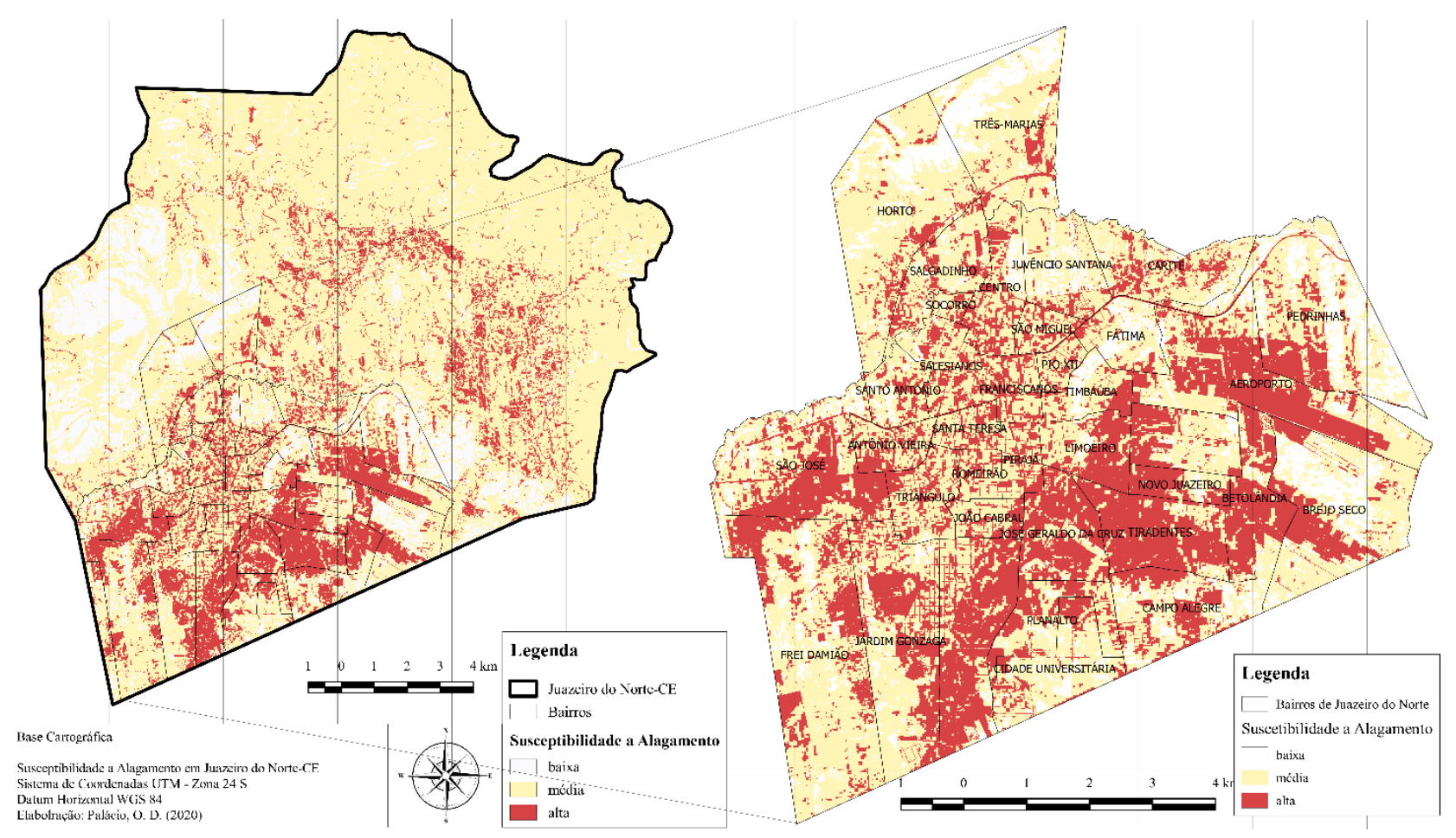

Figura 9. Classes da Susceptibilidade a Alagamento, municipal e urbano, de Juazeiro do Norte, Ceará.

No método aplicado foi considerado o mais apropriado para classificar a área do município, na qual foram selecionados os trabalhos de Soares Neto et al. (2017) e Vojtek e Vojteková (2019), os que mais se adaptaram a região local.

Quanto ao nível de participação das classes susceptíveis para o alagamento (porcentagem de área), foi registrado a classe de alta susceptibilidade com $17 \%$, onde compromete potencialmente a área urbana da cidade e as pequenas porções rurais de baixa declividade, que em alguns espaços acumulam corpos hídricos. $\mathrm{Na}$ sequência, a classe de média susceptibilidade pode comprometer $69 \%$ do município, onde está distribuída espacialmente nas áreas urbanas centrais, nos contornos da cidade e nas zonas rurais de média a baixa declividade. E por fim, a classe de baixa suscetibilidade com $14 \%$ da área total, na qual o alagamento não compromete, apenas, uma pequena parcela do município. Essas porções de terras podem estar associadas às áreas de elevada declividade, de baixo ocupação e de baixos valores de CN. Essas áreas calculadas estão apresentadas na Tabela 2, com suas respectivas porcentagens.

Tabela 2. Porcentagem das classes de susceptibilidade a alagamento que podem aflingir Juazeiro do Norte, Ceará.

\begin{tabular}{ccc}
\hline Susceptibilidade & Área (ha) & Área (\%) \\
\hline Baixa & 3492,86 & 14 \\
Média & 17121,32 & 69 \\
Alta & 4249,75 & 17 \\
\hline Total & 24863,93 & 100 \\
\hline
\end{tabular}

Em sumo, baseado nesses dados, Juazeiro do Norte pode ser considerado um município de média susceptibilidade a alagamento por apresentar uma maior porcentagem nessa classe de contribuição.

Da mesma maneira, ocorre uma maior predominância na média susceptibilidade a alagamento, quando avaliado individualmente a área urbana, em que compreende 52,2\% da área urbana de Juazeiro do Norte.

Embora a área urbana e o município sejam considerados locais de média susceptibilidade, $35,23 \%$ da área urbana estão com elevadíssima 
susceptibilidade a processos de alagamento, o que correspondem a $11 \%$ do município. Esses valores estão inseridos na Tabela 3, abaixo.

Tabela 3. Porcentagem das classes de susceptibilidade a alagamento avaliando individualmente a área urbana de Juazeiro do Norte, Ceará.

\begin{tabular}{ccc}
\hline \multicolumn{3}{c}{ Área Urbana } \\
\hline Susceptibilidade & $($ ha $)$ & $(\%)$ \\
\hline Baixa & 981,12 & 12,57 \\
Média & 4073,20 & 52,20 \\
Alta & 2749,44 & 35,23 \\
\hline Total & 7803,76 & 100 \\
\hline
\end{tabular}

Nesse sentido, dentro desses $35,23 \%$ de elevada susceptibilidade urbana, pode constatar maior prevalência dessa classe nos seguintes bairros: Tiradentes $(79,5 \%)$, Betolândia $(72,8 \%)$, José Geraldo (70,5\%), Lagoa Seca $(69,5 \%)$ e Novo Juazeiro $(62,8 \%)$. Eles apontam como os bairros mais susceptíveis a processos de alagamento quando comparado a todo o perímetro urbano. O bairro Tiradentes é espaço urbano que apresenta, possivelmente, maior evidência desse evento hidrológico, tendo em vista, a elevada classe de susceptibilidade que cobre praticamente toda extensão do bairro (Figura 10).

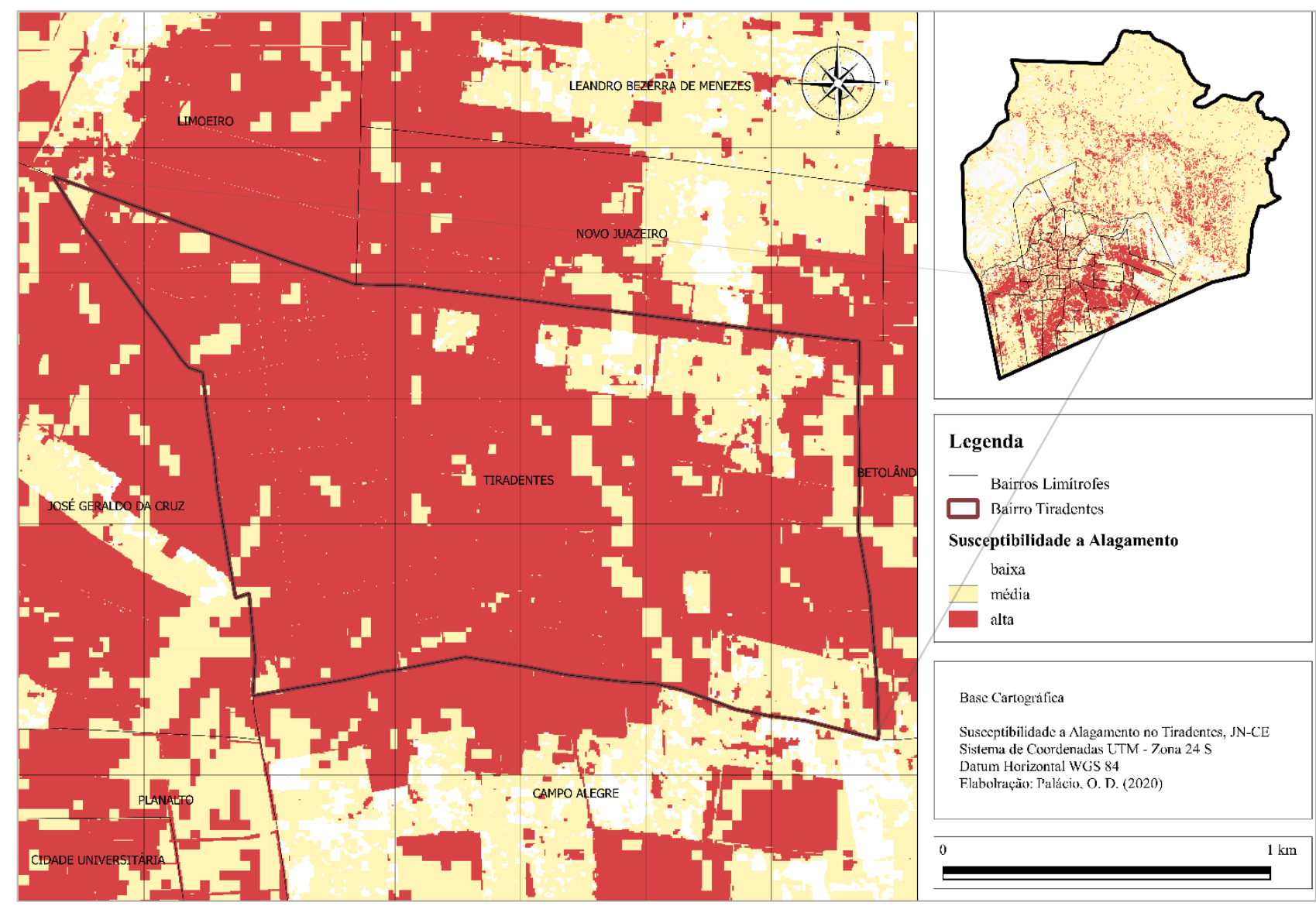

Figura 10. Distribuição espacial da susceptibilidade a alagamento no bairro Tiradentes.

Embora esse bairro seja constituído com solos Argissolos Vermelho-Amarelos (PVA), que tem como característica boa drenagem, sua baixíssima elevação e declividade, além de certos 
níveis de impermeabilização do solo pela ocupação urbana, levam a esse grau de susceptibilidade a alagamento no bairro.

É visto também que, fora os bairros de maior grau de susceptibilidade, destacam-se: o bairro São Miguel, que atenta como o bairro de maior predominância da classe de média susceptibilidade e Leandro Bezerra, com menor possibilidade de haver alagamentos, sendo assim, o bairro mais seguro ou de menor risco a esse evento em Juazeiro do Norte.

De fato, poucos são os registros de alagamento no bairro Leandro Bezerra, visto sua baixa ocupação urbana, com média cobertura de caatinga densa e mata ciliar que elevam a taxa de infiltração na área. Ao contrário dos bairros Tiradentes, Lagoa Seca e Novo Juazeiro, que são presenciados e noticiados, frequentemente, eventos críticos de alagamento, todo início de ano, independentemente da intensidade da quadra chuvosa.

As demais áreas de elevada susceptibilidade associadas à zona rural do município, são justificadas pela falta de cobertura vegetal, pelos baixíssimos níveis de elevação e declividade, pelos Neossolos Flúvicos (RY) e Neossolos Litólicos (RL), solos de imperfeita drenagem, que apontam elevado escoamento superficial e, por conseguinte, acúmulo de água no local. Algumas dessas áreas chegam a se enquadrar como corpos hídricos através dos seus pesos de classe (5) verificadas no estudo. Justifica-se essa adoção por serem áreas de grande acúmulo de água no decorrer do ano, sendo elas, perene ou não.

A respeito da variável declividade, há uma tendência geral, que ocorram conformações mais planas ao longo da área de estudo, elevando a susceptibilidade de alagamentos, na maioria dos trechos. Quando se compara o mapa de declividade com o grau de susceptibilidade, nota-se uma relação direta entre as áreas de maior susceptibilidade com aquelas de conformação mais planas, especialmente quando associadas às áreas urbanas.

Já nos extremos, norte, nordeste e noroeste da unidade de estudo, há acentuadas declividades, em que, consequentemente, apontam baixas susceptibilidades, mesmo em solos de difícil drenagem. Tal fenômeno se justifica pela elevação do relevo que inviabiliza o acúmulo de água no local.

O mapa de susceptibilidade a alagamentos foi comparado com históricos de eventos reais de alagamentos, registrados em noticiários e relatos de moradores, na qual possuem certa concordância. No entanto, pode-se afirmar que, não existe um padrão na literatura que oriente quais e quantas variáveis exatas devem ser aplicadas para a análise de suscetibilidade a alagamento. Assim, há um grau de incerteza nesses estudos, que requerem ser aprimorados, a fim de minimizar margens de erro, com análises mais precisas.

\section{Conclusões}

As variáveis, preconizadas como condicionantes ao alagamento, foram estudas, coletadas, armazenadas e processadas através de geotecnologia (QGIS), gerando um mapa de susceptibilidade a alagamento em Juazeiro do Norte.

Por meio deste mapa, constata-se que, Juazeiro do Norte equivale, possivelmente, a município de média a alta susceptibilidade a alagamento. Este resultado é o reflexo dos critérios físicos do município, como: concentrações de baixas declividades no perímetro urbana da cidade (área pavimentada), área em que possui elevada impermeabilidade; possuir consideráveis $\mathrm{CN}$ ao sudeste e ao sudoeste da área urbana que geram muitas vezes escoamentos acima do que a cidade foi planejada e projetada a receber; além de Juazeiro do Norte possuir menor elevação comparada as demais cidades do CRAJUBAR (Crato e Barbalha), escoando para essa área grande parte do fluxo precipitado na região.

Fora essas características físicas locais, pode haver influência para esse evento, o nível de educação ambiental da população. Nesse sentido, é interessante investigar esse fator, em prol de gerar dados de maior contribuição para o município.

Ademais, pode-se apontar que os critérios físicos avaliados para o município foram decisivos para a detecção de alagamentos, indicando os níveis e áreas de menor a maior sensibilidade. Dessa forma, o mapa de susceptibilidade pode, portanto, ser utilizado para direcionar ações emergenciais de reparos às áreas mais susceptíveis, avaliando a existência ou não de dispositivos de drenagem nesses locais, além de inserir estrategicamente novas medidas que facilitem a drenagem e que reduzam o fluxo de água digressionado a cidade em períodos de precipitação. Também servir de alerta aos gestores para promover ações de conscientização ambiental e sanitária da população, desenvolvendo trabalhos educativos e de fiscalização, de modo a tornar a cidade menos susceptível às situações de alagamento, tão comumente vivenciadas pelos residentes.

Por fim, conclui-se que a integração de dados com uso de geotecnologias (QGIS) contribui de forma eficiente como ferramenta na gestão de drenagem urbana, por fornecer informações representativas de risco hídrico eminente, 
compreendendo assim o suprimento técnico necessário à identificação de pontos sensíveis (susceptíveis) e o planejamento de ações corretivas específicas em curto e longo prazo.

A otimização do mapa pode ser feita abrangendo mais variáveis que possam caracterizar melhor o estado da cidade.

\section{Agradecimentos}

Os autores agradecem ao Conselho Nacional de Desenvolvimento Científico e Tecnológico pelo auxílio financeiro junto ao Edital de número 1/2018 - PRODER/UFCA, à FUNCAP, e a Universidade Federal do Cariri pelo suporte tecnológico.

\section{Referências}

Al-Hinai, H. Y., \& Abdalla, R. (2020). Spatial prediction of coastal flood-susceptible areas in muscat governorate using an entropy weighted method. WIT Transactions on Engineering Sciences, 129(August), 121-133. https://doi.org/10.2495/RISK200111

Ali, S. A., Khatun, R., Ahmad, A., \& Ahmad, S. N. (2019). Application of GIS-based analytic hierarchy process and frequency ratio model to flood vulnerable mapping and risk area estimation at Sundarban region, India. Modeling Earth Systems and Environment, 5(3), 1083-1102. https://doi.org/10.1007/s40808-019-00593-z

Ali, S. A., Parvin, F., Pham, Q. B., Vojtek, M., Vojteková, J., Costache, R., Linh, N. T. T., Nguyen, H. Q., Ahmad, A., \& Ghorbani, M. A. (2020). GIS-based comparative assessment of flood susceptibility mapping using hybrid multi-criteria decision-making approach, naïve Bayes tree, bivariate statistics and logistic regression: A case of Topl'a basin, Slovakia. Ecological Indicators, 117(June). https://doi.org/10.1016/j.ecolind.2020.106620

Avand, M., Moradi, H., \& lasboyee, M. R. (2021). Spatial modeling of flood probability using geoenvironmental variables and machine learning models, case study: Tajan watershed, Iran. Advances in Space Research, 67(10), 31693186. https://doi.org/10.1016/j.asr.2021.02.011

Barros, J. L., Tavares, A. O., \& Santos, P. P. (2021). Land use and land cover dynamics in Leiria City: relation between peri-urbanization processes and hydro-geomorphologic disasters. Natural Hazards, 106(1), 757-784. https://doi.org/10.1007/s11069-020-04490-y

Bui, D. T., Khosravi, K., Shahabi, H., Daggupati, P., Adamowski, J. F., M.Melesse, A., Pham, B.

T., Pourghasemi, H. R., Mahmoudi, M.,
Bahrami, S., Pradhan, B., Shirzadi, A., Chapi, K., \& Lee, S. (2019). Flood spatial modeling in Northern Iran using remote sensing and GIS: A comparison between evidential belief functions and its ensemble with a multivariate logistic regression model. Remote Sensing, 11(13). https://doi.org/10.3390/rs11131589

Costache, R. (2019). Flash-flood Potential Index mapping using weights of evidence, decision Trees models and their novel hybrid integration. Stochastic Environmental Research and Risk Assessment, 33(7), 1375-1402. https://doi.org/10.1007/s00477-019-01689-9

Costache, R., Hong, H., \& Pham, Q. B. (2020). Comparative assessment of the flash-flood potential within small mountain catchments using bivariate statistics and their novel hybrid integration with machine learning models. Science of the Total Environment, 711, 134514. https://doi.org/10.1016/j.scitotenv.2019.13451 4

Dammalage, T. L., \& Jayasinghe, N. T. (2019). Land-Use Change and Its Impact on Urban Flooding: A Case Study on Colombo District Flood on May 2016. Engineering, Technology \& Applied Science Research, 9(2), 3887-3891. https://doi.org/10.48084/etasr.2578

Dano, U. L., Balogun, A. L., Matori, A. N., Yusouf, K. W., Abubakar, I. R., Mohamed, M. A. S., Aina, Y. A., \& Pradhan, B. (2019). Flood susceptibility mapping using GIS-based analytic network process: A case study of Perlis, Malaysia. Water (Switzerland), 11(3). https://doi.org/10.3390/w11030615

Darabi, H., Choubin, B., Rahmati, O., Torabi Haghighi, A., Pradhan, B., \& Kløve, B. (2019). Urban flood risk mapping using the GARP and QUEST models: A comparative study of machine learning techniques. Journal of Hydrology, 569, 142-154. https://doi.org/10.1016/j.jhydrol.2018.12.002

Diaconu, D. C., Costache, R., \& Popa, M. C. (2021). An overview of flood risk analysis methods. Water (Switzerland), 13(4). https://doi.org/10.3390/w13040474

Domakinis, C., Mouratidis, A., Voudouris, K., Astaras, T., \& Karypidou, M. C. (2020). Flood susceptibility mapping in erythropotamos river basin with the aid of remote sensing and GIS. Acta Universitatis Carolinae, Geographica, 55(2), 149-164. https://doi.org/10.14712/23361980.2020.11

Evangelista, A. S., Cavalcante, R. A., Ribeiro, C., Maria, J., \& Silva, O. (2019, junho 11). Mapeamento Geomorfológico do Cariri: a utilização de mapas derivados do MDT. GEOGRAFIA FÍSICA E AS MUDANÇAS 
GLOBAIS, $\quad 1, \quad 1-5$. http://www.editora.ufc.br/images/imagens/pdf/ geografia-fisica-e-as-mudancasglobais/980.pdf

Fernandes, R. de O., Costa, C. T. F. da, \& Studart, T. M. de C. (2017). Soil conservation service. Revista Águas Subterrâneas, 31, 243-254. https://doi.org/10.1007/978-1-4020-39959536

FUNCEME. 2012. Fundação Cearense de Meteorologia e Recursos Hídricos. Levantamento de Reconhecimento de Média Intensidade dos Solos da Mesorregião do Sul Cearense. Fortaleza. Disponível: http://www.funceme.br/?page_id=2787. Acesso: 23 jan. 2020.

Hussain, M., Tayyab, M., Zhang, J., Shah, A. A., Ullah, K., Mehmood, U., \& Al-shaibah, B. (2021). Gis-based multi-criteria approach for flood vulnerability assessment and mapping in district Shangla: Khyber Pakhtunkhwa, Pakistan. Sustainability (Switzerland), 13(6), 130. https://doi.org/10.3390/su13063126

IBGE. (2018). Instituto Brasileiro de Geografia e Estatística. Tabela número de municípios que sofreram com alagamentos (censo de 2010). Disponível:

https://sidra.ibge.gov.br/tabela/2245. Acesso: 3 abr. 2020.

IBGE. (2018). Instituto Brasileiro de Geografia e Estatística. População estimada [2018] para Juazeiro do Norte - CE. Juazeiro do Norte. Disponível:

https://cidades.ibge.gov.br/brasil/ce/juazeirodo-norte/panorama. Acesso: 3 abr. 2020.

INMET, Instituto Nacional de Meteorologia. Série Histórica de 20 anos (1999-2019). Disponível: https://bdmep.inmet.gov.br/. Acesso: 3 abr. 2020.

Jahandideh-Tehrani, M., Zhang, H., Helfer, F., \& Yu, Y. (2019). Review of climate change impacts on predicted river streamflow in tropical rivers. Environmental Monitoring and Assessment, 191(12), 1-23. https://doi.org/10.1007/s10661-019-7841-1

Londe, L. de R., Moura, L. G., Coutinho, M. P., Marchezini, V., \& Soriano, E. (2018). Marchezini Desastres Naturais. Ambiente $e$ Sociedade, 21, 2-24. http://www.scielo.br/pdf/asoc/v21/pt_18094422-asoc-21-e01022.pdf

Mahmoud, S. H., \& Gan, T. Y. (2018). Multicriteria approach to develop flood susceptibility maps in arid regions of Middle East. Journal of Cleaner Production, 196, 216-229. https://doi.org/10.1016/j.jclepro.2018.06.047
Moura-Fé, M. M., Lima, M. T. V, Silva, M. J. A., \& Monteiro, D. A. (2019, junho 11). Urbanização e ocupação das margens dos rios: insustentabilidade ambiental na Regiçao Metropolitana do Cariri (RMC), Ceará. GEOGRAFIA FÍSICA E AS MUDANÇAS GLOBAIS, December, 0-6. http://www.editora.ufc.br/images/imagens/pdf/ geografia-fisica-e-as-mudancasglobais/581.pdf

Moura-fé, M. M., Pinheiro, M. V. A., Silva, J. V. M., \& Nascimento, R. L. (2020). Geodiversidade, Patrimônio e Sustentabilidade na Região Metropolitana do Cariri (RMC), Ceará. In J. F. Sobrinho (Org.), Geodiversidade do Semiárido (p. 155-177). Sertão Cult. https://doi.org/10.35260/87429366

Pereira, C. (2013). Análise socioambiental da cidade de Juazeiro do Norte: subsídios para a construção da Agenda 21 local [UNESP]. In Aleph. http://hdl.handle.net/11449/104415

QGIS.org (2018). QGIS Geographic Information System. Open Source Geospatial Foundation Project. http://qgis.org

Sartori, A., NETO, F., \& Genovez, A. (2005). Classificação Hidrológica de Solos Brasileiros para a Estimativa da Chuva Excedente com o Método do Serviço de Conservação do Solo dos Estados Unidos Parte 1: Classificação. Revista Brasileira de Recursos Hídricos, 10(4), 5-18. https://doi.org/10.21168/rbrh.v10n4.p5-18

Serraj, R., \& Pingali, P. (2018). Agriculture \& Food Systems to 2050. In R Serraj \& P. Pingali (Orgs.), Agriculture \& Food Systems to 2050: Global Trends, Challenges and Opportunities (Vol. 2, Número November 2018, p. 3-45). World Scientific. https://doi.org/10.1142/9789813278356

Silva, E. L. e, Gurgel, H., \& Freitas, C. M. de. (2019). Saúde e desastres no Brasil: uma reflexão sobre os aspectos envolvidos em eventos hidrológicos e rompimento de barragens Santé et catastrophes au Brésil: une réflexion sur les aspects liés aux événements hydrologiques et à la rupture de barrage Health and. Confins, 42. https://doi.org/10.4000/confins.23114

Soares Neto, G. B., Bayma, A. P., Babinski Neto, S., Roig, H. L., \& Menezes, P. H. B. J. (2017). Análise de susceptibilidade a alagamento na bacia hidrográfica do Riacho Fundo - Distrito Federal por meio de Sistemas de Informação Geográfica - SIG. Territorium, 24, 77-87. https://doi.org/10.14195/1647-7723_24_6

Sofia, G., Roder, G., Dalla Fontana, G., \& Tarolli, P. (2017). Flood dynamics in urbanised landscapes: 100 years of climate and humans' 
interaction. Scientific Reports, 7(July 2016), 112. https://doi.org/10.1038/srep40527

Sweya, L. N., \& Wilkinson, S. (2020). A tool for measuring environmental resilience to floods in Tanzania water supply systems. Ecological Indicators, 112 (September 2019), 106165. https://doi.org/10.1016/j.ecolind.2020.106165

Teles, R. P., Silva, M. L. G. da, \& Ribeiro, A. J. A. (2020). Revista Brasileira de Geografia Física. Revista Brasileira de Geografia Física, 06, 1275-1291.

Tien Bui, D., Hoang, N. D., Martínez-Álvarez, F., Ngo, P. T. T., Hoa, P. V., Pham, T. D., Samui, P., \& Costache, R. (2020). A novel deep learning neural network approach for predicting flash flood susceptibility: A case study at a high frequency tropical storm area. Science of the Total Environment, 701, 134413. https://doi.org/10.1016/j.scitotenv.2019.13441 3

Towfiqul Islam, A. R. M., Talukdar, S., Mahato, S., Kundu, S., Eibek, K. U., Pham, Q. B., Kuriqi, A., \& Linh, N. T. T. (2021). Flood susceptibility modelling using advanced ensemble machine learning models. Geoscience Frontiers, 12(3), 101075. https://doi.org/10.1016/j.gsf.2020.09.006

Tucci, C. E. M. (Org.). Hidrologia: ciência e aplicação. Porto Alegre: Editora da Universidade, 1993. ISBN: 978-85-7025-924-0

Vojtek, M., \& Vojteková, J. (2019). Flood susceptibility mapping on a national scale in Slovakia using the analytical hierarchy process. Water (Switzerland), 11(2). https://doi.org/10.3390/w11020364
Wang, Y., Hong, H., Chen, W., Li, S., Panahi, M., Khosravi, K., Shirzadi, A., Shahabi, H., Panahi, S., \& Costache, R. (2019). Flood susceptibility mapping in Dingnan County (China) using adaptive neuro-fuzzy inference system with biogeography based optimization and imperialistic competitive algorithm. Journal of Environmental Management, 247(September 2018), $712-$ 729.https://doi.org/10.1016/j.jenvman.2019.06. 102

Wicaksono, A. D., Hidayah, E., \& Wiyono, R. U. A. (2021). Adaptation, adaptive capacity and vulnerability. Global Environmental Change, $5(3)$,

282-292. https://doi.org/10.1016/j.gloenvcha.2006.03.00 8

Wu, F., Sun, Y., Sun, Z., Wu, S., \& Zhang, Q. (2019). Assessing agricultural system vulnerability to floods: A hybrid approach using emergy and a landscape fragmentation index. Ecological Indicators, 105(June), 337-346. https://doi.org/10.1016/j.ecolind.2017.10.050

Xu, L., Wang, X., Liu, J., He, Y., Tang, J., Nguyen, M., \& Cui, S. (2019). Identifying the trade-offs between climate change mitigation and adaptation in urban land use planning: An empirical study in a coastal city. Environment International, 133(April), 105162. https://doi.org/10.1016/j.envint.2019.105162

Yariyan, P., Avand, M., Abbaspour, R. A., Torabi Haghighi, A., Costache, R., Ghorbanzadeh, O., Janizadeh, S., \& Blaschke, T. (2020). Flood susceptibility mapping using an improved analytic network process with statistical models. Geomatics, Natural Hazards and Risk, 11(1), 2282-2314. https://doi.org/10.1080/19475705.2020.183603 6 